\title{
Efisiensi Termal Boiler Menggunakan Bahan Bakar Campuran Batubara Lignit dan Cangkang Biji Jambu Mete
}

\author{
(The Thermal Efficiency of a Steam Boiler Uses a Mixture of Lignite Coal and Cashew Nut Shells)
}

\author{
NOVARINI, SUKADI
}

\begin{abstract}
ABSTRAK
Cadangan bahan bakar batubara saat ini menurun, sehingga perlu dilakukan upaya untuk meminimalkan penggunaan bahan bakar ini. Provinsi Sulawesi Tenggara adalah produsen mete terbesar di Indonesia di mana kulit kacang mete dapat digunakan sebagai alternatif campuran bahan bakar batubara. Penelitian ini bertujuan untuk memperoleh nilai efisiensi termal maksimum pada pembakaran batubara di boiler dengan kapasitas 10,5 ton/jam dengan memvariasikan campuran bahan bakar batubara lignit dan kulit kacang mete dengan komposisi campuran $60 \%$ : 40\%, 50\%: 50\% , 40\%: 60\%, 30\%: 70\%, 20\%: 80\%, dan 10\%: 90\%. Data yang diambil adalah hasil analisis proksimat dan pamungkas kulit lignit dan kacang mete serta data teknis operasi boiler tipe firetube. Hasil penelitian menunjukkan bahwa efisiensi termal maksimum 88,75\% adalah dengan menggunakan $10 \%$ campuran batubara lignit dan $90 \%$ kulit kacang mete.
\end{abstract}

Kata kunci: batubara lignit, kulit mete, boiler firetube, efisiensi termal

\section{ABSTRACT}

Coal fuel reserves are currently decreasing, so efforts need to be made to minimize the use of these fuels. Southeast Sulawesi Province is the largest cashew producer in Indonesia where the cashew nut shell can be used as an alternative to coal fuel mixture. This research aims to obtain maximum thermal efficiency value of a coal fires steam boiler with a capacity of 10.5 tons/hour by varying the mixture of lignite coal fuel and cashew nut shell with mixed composition of 60\%:40\%, 50\%: $50 \%$, $40 \%: 60 \%, 30 \%: 70 \%, 20 \%: 80 \%$, and 10\%:90\%. The data taken are the result of proximate and ultimate analysis of lignite and cashew nut shells and also technical operation data of steam pipe boiler. The results showed that the maximum thermal efficiency $88.75 \%$ was by using $10 \%$ mixture of lignite coal and $90 \%$ cashew nutshell.

Keywords: lignite coal, cashew nut shells, fire tube steam boiler, thermal efficiency

\section{PENDAHULUAN}

Energi konvensional berupa minyak bumi, gas dan batubara merupakan sumber energi yang tidak dapat diperbarui. Peningkatan jumlah penduduk mempengaruhi peningkatan konsumsi energi tersebut dikarenakan untuk proses produksi di industri meningkat guna mencukupi kebutuhan masyarakat. Indonesia merupakan negara yang mayoritas industrinya masih mengunakan bahan bakar fosil. Prediksi para pakar energy kedepannya Indonesia akan terjadi krisis energi dengan semakin menipisnya bahan bakar fosil.

Boiler merupakan equipment ang sangat penting dalam proses di indusri, dimana bahan bakar yang banyak digunakan berupa batubara yang merupakan kelompok bahan bakar tak terbarukan. Permasalahan krisis energi tersebut mengharuskan kita mencari alternatif bahan bakar untuk mengantikan batubara atau 
setidaknya mengurangi pemakaian batubara untuk boiler.

Makassar merupakan daerah yang banyak terdapat jambu mete. Daerah ini terdapat industri dimana salah satu bahannya berupa biji jambu mete. Proses pengolahan biji jambu mete tersebut dihasilkan limbah berupa cangkang biji jambu mete yang belum dimanfaatkan secara maksimal. Berdasarkan permasalahan energi tersebut, dipandang dengan ketersediaan cangkang biji jambu mete bisa menjadi solusi untuk mengurangi pemakaian batubara.

Berdasarkan penelitian (Novarini, Siahaya, \& Leonard, 2014) didapatkan data Biji jambu mete terdiri dari $70 \%$ kulit biji dan 30\% daging biji. Kulit biji (shell) mengandung minyak sekitar $50 \%$ yang terdiri dari $80,9 \%$ asam anakardat, $\quad 13,78 \%$ fenol yang biasa disebut kardol, 1,59\% kardanol dan 2,64\% 2 metil kardol. Batubara produksi rakyat dari Kecamatan Malawa Kabupaten Bone Provinsi Sulawesi Selatan. Batubara ini termasuk dalam klasifikasi batubara range lignit yang ditentukan oleh analisa ultimate karena pemeringkatan batubara tergantung dari sifat dan keberadaan unsur-unsur $\mathrm{C}, \mathrm{H}_{2}, \mathrm{~S} \mathrm{O}_{2}$ dan $\mathrm{N}_{2}$ sedangkan analisa proximate dibutuhkan guna memperkirakan kinerja bahan bakar (batubara maupun cangkang biji jambu mete) dalam proses pembakaran.

Menurut (Baldi, Quang, Holub, \& Endel, 2017) Boiler yang memanfaatkan gas buang untuk memanaskan kembali air umpan yang masuk ke boiler dapat meningkatkan efisiensi sebesar 10$12 \%$, sedangkan menurut (Barma et al., 2017)pemeliharaan yang dilakukan secara terjadwal pada boiler dan pemafaatan gas buang dapat meningkatkan effisiensi termal.

Adapun faktor yang dapat mempengaruhi efisiensi termal pada boiler adalah suhu gas buang dan rasio volatil bahan bakar (Chao et al. 2017), sedangkan (Gao, Qi, Lyu, Chen, \&
Huang, 2017) menyatakan pengontrolan sistem operasi pada boiler secara online terhadap umpan bahan bakar, proses pembakaran yang mencakup rasio bahan bakar dan gas pembakaran bisa meningkatkan efisiensi termal.

Dilakukan penelitian efisiensi boiler dengan bahan bakar campuran batubara kelas rendah dan sekam padi dimana bahan bakar yang tidak terbakar secara sempurna di bagian bawah ruang pembakaran yang menyebabkan turunnya efisiensi termal boiler (Patro, 2016).

Efisiensi termal pembangkit tenaga nuklir dipengaruhi oleh tiga parameter regenerasi air umpan berupa distribusi enthalpy untuk menaikkan panas, suhu air umpan optimum yang sesuai dan jumlah tahap regenerative ( $\mathrm{Su}$, Chaudri, Tian, Su, \& Qiu, 2014).

Metode pencampuran jumlah pemakaian bahan bakar $75 \%$ serabut kelapa sawit (fiber) dan $25 \%$ untuk cangkang kelapa sawit (shell) menggunakan perhitungan efisiensi termal menggunakan neraca massa dan energi diperoleh efisiensi termis tertinggi sebesar 89,29\% (Patisarana \& Hazwi, 2012).

Boiler merupakan salah satu dari jenis Heat Exchanger (HE), dimana penggunaan perbandingan bahan bakar dan udara pembakaran yang tepat pada HE dapat menghasilkan pembakaran sempurna dan meningkatkan gas hasil pembakaran $\mathrm{CO}_{2}$ sehingga menghemat penggunaan bahan bakar dapat dihemat serta efisiensi pada HE juga meningkat. (Irawan, 2017)

\section{METODE PENELITIAN}

Dalam penelitian akan dihitung efisiensi termal boiler dengan memvariasikan campuran bahan bakar cangkang biji jambu mete dan batubara lignit Malawa Makasar. Pencampuran bahan bakar berdasarkan Tabel 1.

TABEL 1. Variasi campuran bahan bakar boiler

\begin{tabular}{ccccccc}
\hline $\begin{array}{c}\text { Bahan } \\
\text { bakar }\end{array}$ & \multicolumn{5}{c}{ Rasio (\%) } \\
\hline $\begin{array}{c}\text { Cangkang } \\
\text { biji jambu } \\
\text { mete }\end{array}$ & 10 & 20 & 30 & 40 & 50 & 60 \\
$\begin{array}{c}\text { Batubara } \\
\text { lignit }\end{array}$ & 90 & 80 & 70 & 60 & 50 & 40 \\
\hline
\end{tabular}




\section{Metode}

Perhitungan Efisiensi termal boiler berdasarkan Kitto \& Stultz, dilakukan melalui tahapan sebagai berikut :

1. Perhitungan proximate campuran bahan bakar meliputi komposisi Ash dan $\mathrm{H}_{2} \mathrm{O}$

2. Perhitungan Ultimate campuran bahan bakar meliputi komposisi C, H2, O2, N2, S dan HHV

3. Pengumpulan data teknis dan operasional boiler:

Type boiler : Firetube ALSTOM kapasitas 10,5 ton/h ditunjukkan pada gambar 1.

Data teknis boiler berupa luas furnace didapatkan dari manual book boiler sedangkan data tekanan uap/steam, temperatur gas keluar pipa api, excess air/udara berlebih dibaca dari panel control boiler. Temperatur dan tekanan air umpan diambil dari pembacaan instrument temperature dan tekanan pada feed water tank. Data temperature steam didapatkan dengan melihat tabel steam mengacu pada tekanan steam yang telah diperoleh dan hasil penimbangan sisa karbon di conveyor menuju furnace di akhir operasi boiler dicatat sebagai jumlah carbon yang tidak terbakar. Berikut data teknis dan operasional yang didapatkan :
a. Temperatur uap/steam
: $162^{\circ} \mathrm{C}=324^{\circ} \mathrm{F}$
b. Tekanan uap/steam
$: 561 \mathrm{kPa}$
c. Laju alir uap/steam $\left(\mathrm{m}_{\mathrm{s}}\right)$
$: 5.750 \mathrm{~kg} / \mathrm{h}$
d. Temperatur air umpan
: $81^{\circ} \mathrm{C}=177^{\circ} \mathrm{F}$
e. Tekanan air umpan
: $0,49 \mathrm{bar}$
f. Laju alir air umpan
: $5.750 \mathrm{~kg} / \mathrm{h}$
g. Temperatur gas keluar pipa api : $208^{0} \mathrm{C}=$ $406^{\circ} \mathrm{F}$
h. Excess air/udara berlebih : $26 \%$
i. Jumlah carbon yang tidak terbakar : $0,14 \%$
j. Luas furnace
$: 851,61 \mathrm{ft} 2$

4. Perhitungan prestasi kerja boiler menggunakan combustion calculationBTU Method

5. Perhitungan entalpi steam $\left(\mathrm{h}_{\mathrm{s}}\right)$ dan entalpi air umpan $\left(\mathrm{h}_{1}\right)$

6. Menentukan laju alir bahan bakar/fuel $\left(\mathrm{m}_{\mathrm{f}}\right)$ dari combustion calculation - BTU Method

7. Perhitungan kesetimbangan energi sesuai dengan gambar 2.

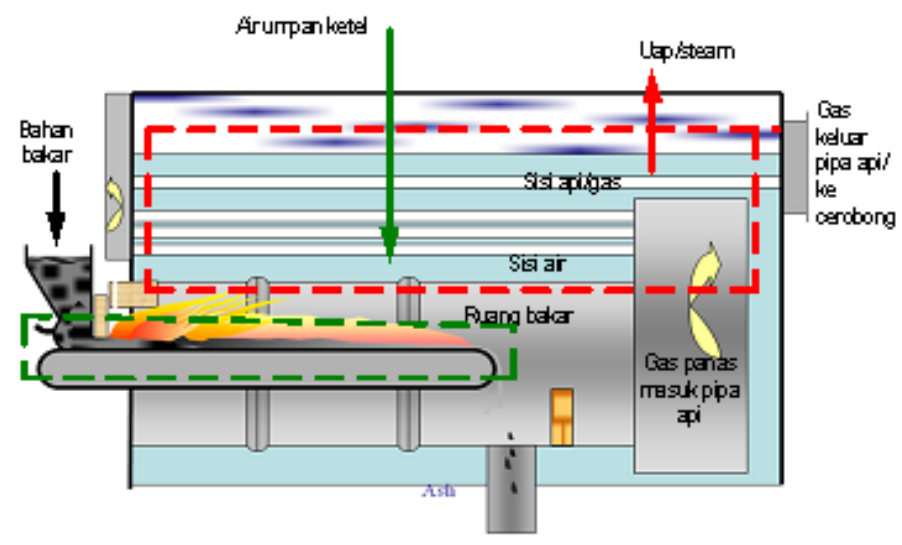

GAMBAR 1. Boiler tipe Firetube

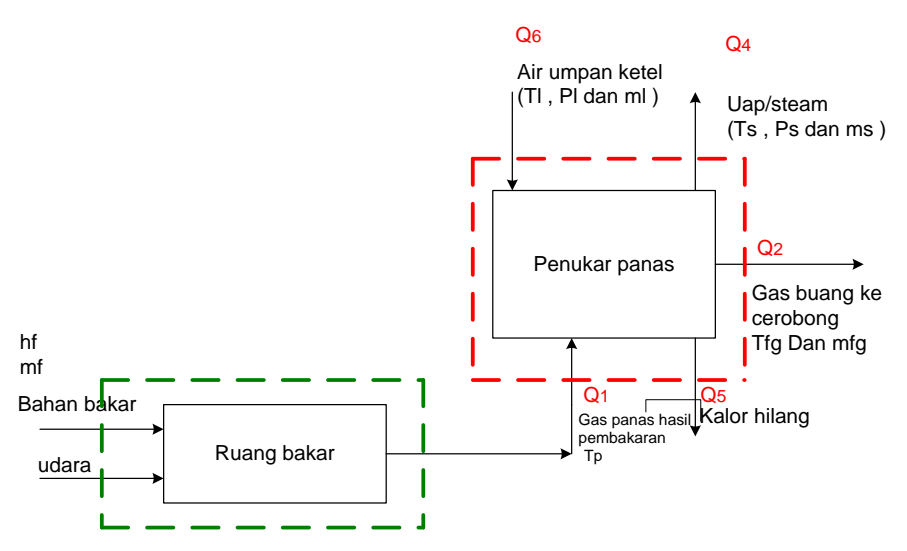

GAMBAR 2. Kesetimbangan Energi, (Kitto \& Stultz, 2015) 
Kesetimbangan energi atau kalor pada boiler digambarkan pada Gambar 1, dimana boiler terdiri dari ruang bakar/furnace dan Heat Exchanger/Ruang bakar. Kalor input pada Heat Exchanger atau Penukar kalor terdiri dari 2 sisi yaitu $\mathrm{Q}_{1}$ dari hasil gas pembakaran pada furnace (hot product) dan $\mathrm{Q}_{6}$ sebagai kalor dari air umpan masuk pada Heat Exchanger. Kalor output terdiri dari 3 sisi yaitu steam yang dibangkitkan dari hasil perpindahan panas pada Heat Exchanger sebagai $\mathrm{Q}_{4}$, Kalor gas sisa keluar cerobong sebagai $\mathrm{Q}_{2}$ dan Kalor yang hilang pada proses perpindahan panas sebagai
$\mathrm{Q}_{5}$. Selisih penjumlahan $\mathrm{Q}_{1}$ dan $\mathrm{Q}_{6}$ dan $\mathrm{Q}_{2}$ dan $\mathrm{Q}_{4}$ adalah dihitung senagai $\mathrm{Q}_{5}$. Sedangkan efisiensi boiler didapatkan dengan menghitung selisih kalor steam yang dibangkitkan dikurangi kalor yang hilang terhadap besar kalor yang dihasilkan dari gas panas dari furnace.

$$
\begin{array}{ll}
\mathrm{Q}_{1}(\text { Hot product }) & =\mathrm{m}_{\mathrm{f}} \times \mathrm{HHV} \\
\mathrm{Q}_{4} \text { (steam yang dibangkitkan) } & =\mathrm{m}_{\mathrm{s}} \times \mathrm{h}_{\mathrm{s}} \\
\mathrm{Q}_{6} \text { (air umpan boiler) } & =\mathrm{m}_{1} \times \mathrm{h}_{1}
\end{array}
$$

TABEL 2. Analisa proximate batubara lignit malawa dan cangkang biji jambu mete

\begin{tabular}{cccc}
\hline Analisa proximate & Unit & $\begin{array}{c}\text { Batubara Lignit } \\
\text { Malawa }\end{array}$ & $\begin{array}{c}\text { Cangkang Biji } \\
\text { Jambu Mete }\end{array}$ \\
\hline Moisture & $\%$ & 9,20 & 8,85 \\
Volatiles & $\%$ & 42,80 & 68,03 \\
Carbon & $\%$ & 37,10 & 21,12 \\
Ash & $\%$ & 10,90 & 2,00 \\
HHV & Btu/lb & 11230 & 9101 \\
\hline
\end{tabular}

TABEL 3. Analisa ultimate batubara lignit malawa dan cangkang biji jambu mete

\begin{tabular}{cccc}
\hline Analisa Ultimate & Unit & $\begin{array}{c}\text { Batubara Lignit } \\
\text { Malawa }\end{array}$ & $\begin{array}{c}\text { Cangkang Biji } \\
\text { Jambu Mete }\end{array}$ \\
\hline $\mathrm{C}$ & $\%$ & 65,55 & 46,08 \\
$\mathrm{H}_{2}$ & $\%$ & 4,94 & 3,88 \\
$\mathrm{~S}$ & $\%$ & 3,10 & - \\
$\mathrm{O}_{2}$ & $\%$ & 5,20 & 38,98 \\
$\mathrm{~N}_{2}$ & $\%$ & 1,16 & 0,21 \\
$\mathrm{H}_{2} \mathrm{O}$ & $\%$ & 9,20 & 8,85 \\
$\mathrm{Ash}$ & $\%$ & 10,90 & 2,0 \\
\hline
\end{tabular}

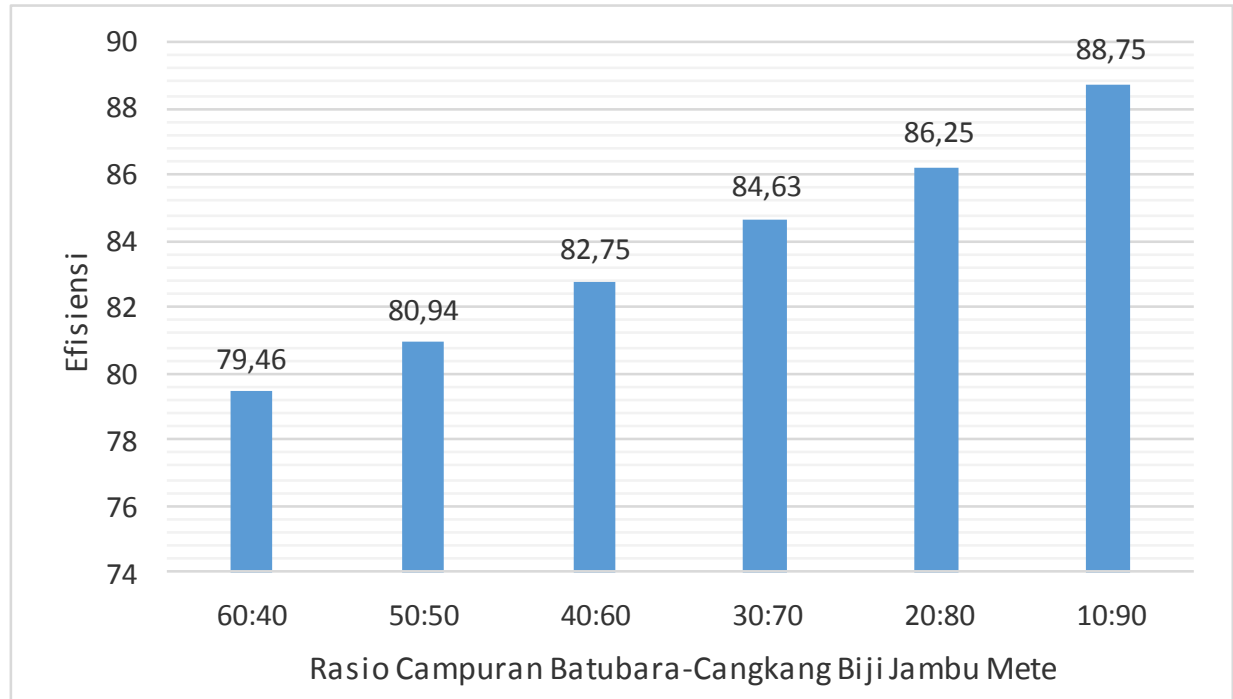

GAMBAR 3. Grafik efisiensi variasi bahan bakar batubara lignit mallawa dan cangkang biji jambu mete terhadap efisiensi termal boiler 


\section{HASIL DAN PEMBAHASAN}

Sifat-sifat batubara lignit Malawa dan cangkang biji jambu mete disajikan pada Tabel 2 dan Tabel 3.

Dari hasil perhitungan yang dilakukan menggunakan combustion calculation - BTU Method dapat dilihat perbedaaan effisiensi termal dari variasi campuran bahan bakar yang diuji pada Gambar 3.

Pada grafik tersebut dapat dilihat bahwa terjadi peningkatan efisiensi termal boiler jika dilakukan penambahan cangkang biji jambu mete. Penambahan cangkang biji jambu mete dapat meningkatkan efisiensi boiler karena cangkang biji jambu mete memiliki kandungan ash atau abu yang jauh lebih rendah dibanding dengan batubara lignite, batubara lignite $10,90 \%$ sedangkan cangkang biji jambu mete hanya 2\%. Partikel abu pada batubara merupakan sumber deposit atau endapan pada permukaan dinding bagian-bagian ketel uap yang menghalangi proses perpindahan panas pada ketel uap. Endapan yang terbentuk dari abu ini bisa terbagi dua, yaitu slagging dan fouling.

Slagging merupakan endapan yang terbentuk pada ruang bakar yang mengakibatkan terhambatnya perpindahan panas dari ruang bakar ke sisi air. Fouling merupakan fenomena menempelnya dan menumpuknya abu terbang yang terbawa pada gas hasil pembakaran dalam pipa api akibat adanya penurunan temperatur, fouling mengakibatkan terhambatnya perpindahan panas dari sisi pipa api ke sisi pipa air.

Selain kandungan abu, kandungan air pada cangkang biji jambu mete juga lebih rendah dibanding kandungan air pada batubara lignite, batubara lignite 9,2\% sedangkan cangkang biji jambu mete $8,85 \%$ sehingga proses pembakaran akan lebih cepat karena bila kadar air tinggi dibutuhkan waktu untuk menguapkan air terlebih dahulu sebelum kemudian proses pembakaran Carbon menjadi $\mathrm{CO} 2$ sebagai sumber kalor.

Nilai volatile matter atau zat terbang pada cangkang biji jambu mete juga lebih tinggi dibanding batubara lignite, batubara lignite $42,80 \%$ sedangkan cangkang biji jambu mete $68,03 \%$. Kandungan volatile matter yang tinggi pada cangkang biji jambu mete membantu proses penjalaran api lebih cepat untuk pembakaran.

Efisiensi termal maksimal sebesar $88,75 \%$ didapatkan pada campuaran dengan perbandingan $10 \%$ batubara lignit Malawa dan $90 \%$ cangkang biji jambu mete. Nilai ini sudah cukup mendekati dengan nilai kajian teknis dan ekonomis penelitian yang dilakukan oleh (Akhdiyatul, Radwitya, \& Chandra, 2018) dalam mengganti batubara dengan cangkang kelapa sawit dengan perlakuan awal pengeringan cangkang kelapa sawit didapatkan nilai efisiensi sebesar $90 \%$.

\section{KESIMPULAN}

Efisiensi termal boiler tertinggi yaitu $88,75 \%$ didapatkan pada pemakaian campuran bahan bakar dengan perbandingan $10 \%$ batubara lignit mallawa dan $90 \%$ cangkang biji jambu mete sehingga perbandingan ini dapat dijadikan panduan untuk proses pencampuran penggunaan bahan bakar batubara dan cangkang biji jambu mete untuk jenis boiler firetube lainnya.

\section{DAFTAR PUSTAKA}

Akhdiyatul, Radwitya, E., \& Chandra, Y. (2018). Analisis Teknis dan Ekonomis Dalam Penggunaan Bahan Bakar Biomassa Di Pusat Listrik Tenaga Uap Studi Kasus di PLTU PT . Suka Jaya Makmur. ELKHA: Jurnal Teknik Elektro, 10(2), 49-55.

Baldi, S., Quang, T. Le, Holub, O., \& Endel, P. (2017). Real-time monitoring energy efficiency and performance degradation of condensing boilers. Energy Conversion and Management, 136, 329-339. https://doi.org/10.1016/j.enconman.2017.0 1.016

Barma, M. C., Saidur, R., Rahman, S. M. A., Allouhi, A., Akash, B. A., \& Sait, S. M. (2017). A review on boilers energy use, energy savings, and emissions reductions. Renewable and Sustainable Energy Reviews, 79(March 2016), 970-983. https://doi.org/10.1016/j.rser.2017.05.187 
Gao, X., Qi, L., Lyu, W., Chen, T., \& Huang, D. (2017). RIMER and SA based thermal efficiency optimization for fired heaters. Fuel, 205 , 272-285. https://doi.org/10.1016/j.fuel.2017.05.067

Irawan, B. (2017). Perhitungan Energi Pembakaran Bahan Bakar di Dalam Silinder Mesin Bensin Perhitungan Energi Pembakaran Bahan Bakar di Dalam Silinder Mesin Bensin. In SNTT 2017 (pp. 13-16). Malang: Politeknik Negeri Malang.

Kitto, J. B., \& Stultz, S. C. (2015). Steam (42nd ed.). Ohio USA: The Babcock and Wilcox Company Barbeton.

Novarini, Siahaya, Y., \& Leonard, J. (2014). Novarini. In Penggunaan Batubara Lignit Mallawa Dan Pencampuran Dengan Cangkang Biji Jambu Mete Di PT. Indofood CBP, Tbk Cabang Makassar (pp. 78-61). Makasar: Prosiding Seminar Nasional Rekayasa Material, Sistem Manufaktru dan Energi.

Patisarana, G., \& Hazwi, M. (2012). Optimalisasi efisiensi termis boiler menggunakan serabut dan cangkang sawit sebagai bahan bakar. Dinamis, I(11), 2226.

Patro, B. (2016). Efficiency stud ies of combination tube boilers. Alexandria Engineering Journal, 55(1), 193-202. https://doi.org/10.1016/j.aej.2015.12.007

Su, Y., Chaudri, K. S., Tian, W., Su, G., \& Qiu, S. (2014). Optimization study for thermal efficiency of supercritical water reactor nuclear power plant. Annals of Nuclear Energy, 63, 541-547. https://doi.org/10.1016/j.anucene.2013.08. 023

PENULIS:

Novarini

Program Studi Teknik Mesin, Politeknik Jambi, Jalan Lingkar Barat 1, Bagan Pete, Kota Baru, Jambi

Email: novarini@politeknikjambi.ac.id
Sukadi

Program Studi Teknik Mesin, Politeknik Jambi, Jalan Lingkar Barat 1, Bagan Pete, Kota Baru, Jambi

Email: sukadiadi4n4@gmail.com 